\title{
Combined ESEM and CT Scan: The process of salt weathering
}

\author{
Eric Doehne*, David Carson* and Alessandro Pasini** \\ *The Getty Conservation Institute, 1200 Getty Center Drive, Suite 700, Los Angeles, CA 90049 \\ **University of Bologna, Italy
}

While the Environmental Scanning Electron Microscope (ESEM) allows high-resolution characterization of material surfaces in their natural state, access to data in the third dimension is often necessary to realistically evaluate the condition of dynamic systems, such as the weathering processes affecting monuments and sculpture. Data presented here show that X-ray Microtomography (CT [1] and micro-CT) can provide an important supplement to ESEM/EDS microanalysis when studying the deterioration of stone by the sub-surface crystallization of magnesium sulfate salts.

Magnesium limestone is widely used in historic architecture and monuments, especially in the north of England. York Minster, the largest gothic cathedral in Northern Europe, is also located near one of Europe's largest coal fired powerplants. Magnesium sulfate salts, produced by the reaction between the stone and airborne sulfate tend to accumulate in sheltered areas and crystallize episodically beneath the stone surface.

This crystallization reaction was studied using oolitic limestone test blocks and saturated magnesium sulfate solution setup in the laboratory so that continuous crystallization would occur from a reservoir [Fig. 1]. CT data was acquired using a standard $450 \mathrm{kV}$ Philips industrial X-radiography setup modified with a new detector comprised of a mirror, Apogee high resolution camera, and cesium iodide scintillator screen along with software developed by Dr. Pasini and the University of Bologna.

The preliminary results of the study show that the crystallization takes place in a zone parallel to the stone surface that appears to leave the stone interior largely intact. ESEM results show two morphological types of salt crystals: anhedral at the stone/salt interface and columnar as the salt separates the stone layer from the stone core. CT results show several distinct density zones, which appear to correspond to the degree of disruption of the stone [Fig. 2].

\section{References}

[1] V.G. Mossotti and L.M. Castanier, The measurement of water transport in Salem limestone by xray computer aided tomography, in International symposium on The engineering geology of ancient works, monuments and historical sites; preservation and protection, P.G. Marinos and G.C. Koukis, Editors. 1990, Balkema: Rotterdam. p. 2079-2082.

[2] Acknowledgements: The support of Dr. Giacomo Chiari and Dr. Franco Casali in this research is gratefully acknowledged. 

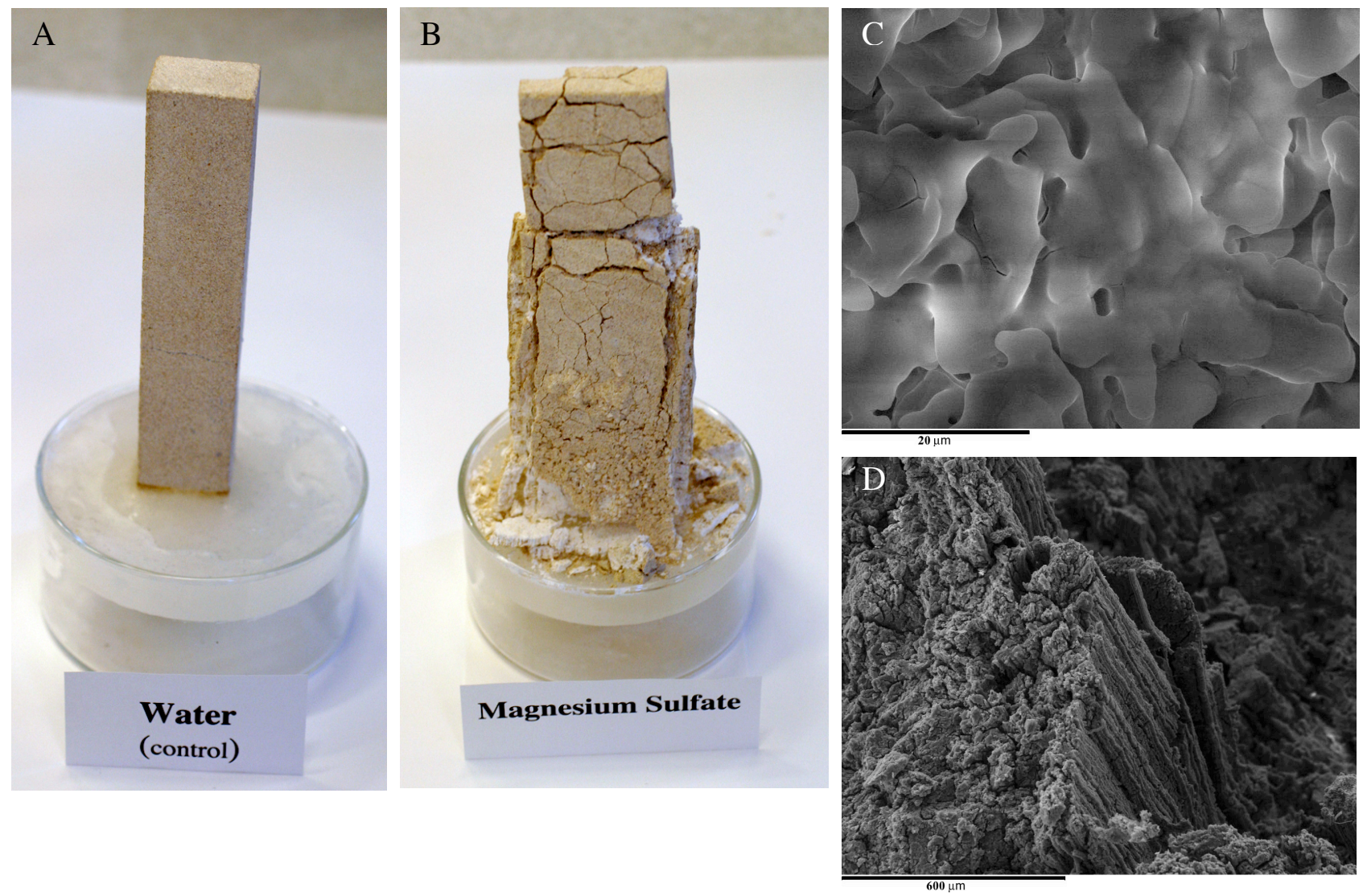

Figure 1. A\&B) Experimental setup C) Anhedral magnesium sulfate crystals at the salt-stone interface D) Columnar magnesium sulfate crystals between outer stone layer and stone core.
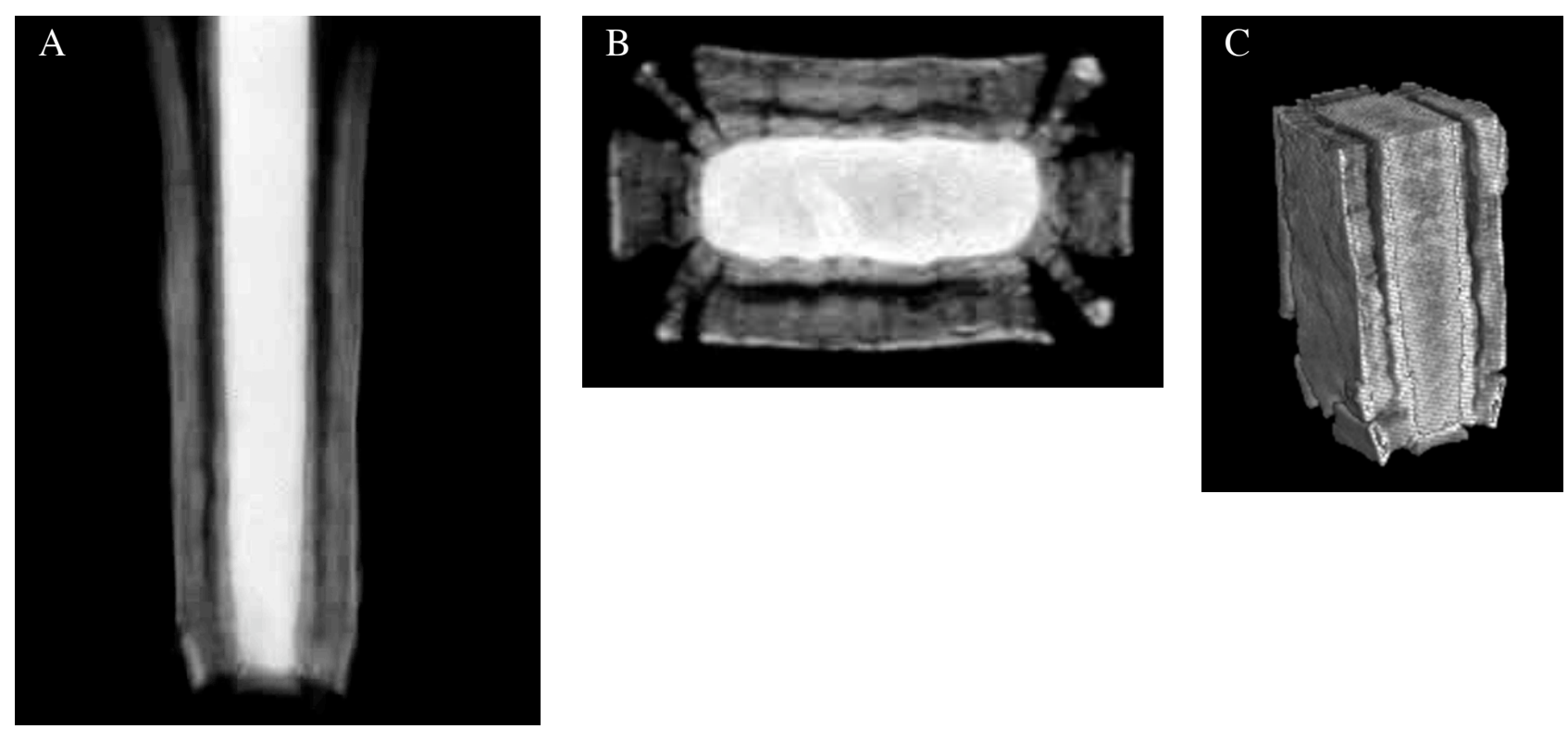

Figure 2. CT images of the salt impregnated stone block. A) Vertical CT slice showing detachment. B) Horizontal CT slice showing density difference between stone core and salt layers. C) 3D reconstruction using VGStudio Max software. 